\title{
Is Sleep Disruption a Cause or Consequence of Alzheimer's Disease? Reviewing Its Possible Role as a Biomarker
}

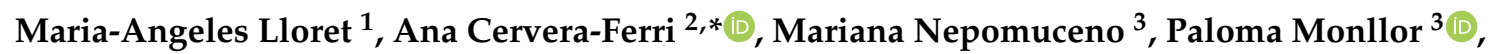 \\ Daniel Esteve $^{3}$ and Ana Lloret ${ }^{3}$ (B) \\ 1 Department of Clinical Neurophysiology, University Clinic Hospital of Valencia, Avda. Blasco Ibanez, 17, \\ 46010 Valencia, Spain; malloretalc@gmail.com \\ 2 Department of Human Anatomy and Embryology, Faculty of Medicine, University of Valencia, Avda. Blasco \\ Ibanez, 15, 46010 Valencia, Spain \\ 3 Department of Physiology, Faculty of Medicine, University of Valencia, Health Research Institute INCLIVA, \\ Avda. Blasco Ibanez, 15, 46010 Valencia, Spain; mary.pinheiro@gmail.com (M.N.); \\ paloma.monllor@uv.es (P.M.); daniel.esteve@ext.uv.es (D.E.); ana.lloret@uv.es (A.L.) \\ * Correspondence: ana.cervera-ferri@uv.es; Tel.: +34-9639-835-07
}

Received: 27 December 2019; Accepted: 8 February 2020; Published: 10 February 2020

\begin{abstract}
In recent years, the idea that sleep is critical for cognitive processing has gained strength. Alzheimer's disease (AD) is the most common form of dementia worldwide and presents a high prevalence of sleep disturbances. However, it is difficult to establish causal relations, since a vicious circle emerges between different aspects of the disease. Nowadays, we know that sleep is crucial to consolidate memory and to remove the excess of beta-amyloid and hyperphosphorilated tau accumulated in AD patients' brains. In this review, we discuss how sleep disturbances often precede in years some pathological traits, as well as cognitive decline, in AD. We describe the relevance of sleep to memory consolidation, focusing on changes in sleep patterns in AD in contrast to normal aging. We also analyze whether sleep alterations could be useful biomarkers to predict the risk of developing AD and we compile some sleep-related proposed biomarkers. The relevance of the analysis of the sleep microstructure is highlighted to detect specific oscillatory patterns that could be useful as AD biomarkers.
\end{abstract}

Keywords: REM; NREM; SWS; SWA; Spindles; CSF amyloid; CSF tau

\section{Introduction}

There is cumulating evidence that sleep quality and duration are relevant to cognitive processes. Cognitive impairments and sleep disturbances are often associated with several pathological conditions, although the nature of these relationships is still unclear and it is difficult to establish causal relations. Alzheimer's disease (AD) is one of these conditions and it is also the most common form of dementia worldwide. Classically, it starts with a decline in episodic memory; however, neuropsychiatric symptoms can be present very early on and they can make an early diagnosis difficult $[1,2]$.

AD presents a high prevalence and severity of sleep alterations [3-5] with research showing that sleep disturbances often precede in years the diagnosis of $\mathrm{AD}$ and that they might appear even before cognitive decline [6]. In fact, a longitudinal epidemiological study linked poor sleep quality in healthy people with cognitive impairment one year later [7]. Lim et al., in a community-based, prospective study, found that people with high sleep fragmentation had a 1.5-times higher risk of developing AD in a 6 years follow-up period [8]. Likewise, Benedict et al. conducted a 40-year study that evaluated 1574 men aged 50 and older, and observed that people with sleep disturbance had a 51\% increase in 
the risk of developing AD [9]. Similarly, Bubu and colleagues estimated in a meta-analysis that the risk of dementia in patients with sleep disorders was 1.68 times greater [10]. Moreover, in a recent multi-center study, both midlife and late-life terminal insomnia were associated with a higher risk of dementia [11].

It is interesting to note that affected brain structures in people with disturbed sleep coincide with vulnerable areas in AD. Lower gray matter volume in hippocampus, precuneus, amygdala, and cingulate gyrus [12-19], and a higher degree of cortical atrophy have been described in cognitively-unimpaired insomnia patients [14,20]. A recent study performed in cognitively unimpaired adults aged between 45 and 75, found that insomnia patients presented decreases in grey matter volume in AD-related areas, that concur with other studies. Furthermore, they found greater volume in the left caudate in these subjects, which can also be seen in presymptomatic carriers of an AD genetic mutation [21]. Finally, a very recent study in middle-aged, cognitively unimpaired adults found lower grey matter volumes in the left angular gyrus, the bilateral superior frontal gyri, the thalami, and the right hippocampus in insomniac APOE- $\varepsilon 4$ carriers (AD's main risk factor) when compared to non-carriers with or without insomnia [21].

This temporal and anatomical relationship could suggest that sleep disturbances may influence or exacerbate $\mathrm{AD}$ pathology and that improving sleep may help slow down its progression [22,23]. Additionally, sleep alterations could be used to predict the risk of developing dementia and could also serve as early indicators of the disease. If sleep disorders constitute a risk factor to initiate or to accelerate the clinical course of AD, they could be used to develop disease biomarkers. Furthermore, a sleep biomarker with high sensitivity and specificity would be extremely useful, as electrophysiological recordings are noninvasive and relatively inexpensive.

In this manuscript we aim to review sleep disorders' association with the neuropathological basis of $\mathrm{AD}$, in an attempt to shed some light on the possible causal nature of this relationship and sleep's plausible role as biomarker. We will first focus on the relevance of sleep for memory consolidation, followed by a brief review of sleep disturbances and of sleep and memory patterns with aging. Next, we will emphasize sleep disturbances in AD, either as clinical manifestations or as risk factors, and we will compile and discuss oscillatory, biochemical and system-based mechanisms linking sleep disturbances and the pathology of the disease. Finally, we will discuss the relationship between sleep disruption and gold standard AD biomarkers, as well as several sleep alterations that have been proposed as possible biomarkers for the early detection of AD.

\section{Role of Sleep in Declarative Memory Consolidation}

Declarative memory is hippocampal-dependent both in early stages of memory consolidation and also in recall [24] and after consolidation occurs, memories become hippocampal-independent [25]. Specifically in AD, declarative episodic memory is affected in the early stages, while other types of memory only deteriorate as the disease progresses [2,26-28].

The active systems consolidation hypothesis is currently one of the most important theories on the mechanisms of declarative memory consolidation. It focuses on the interaction between neocortex and hippocampus during sleep. After encoding, memories are labile and highly dependent on the hippocampus. To create more stable long-term memories, the hippocampal representations are repeatedly reactivated during sleep. These reactivations coactivate neocortical areas that will integrate the new representations into preexisting memories [29].

Ample evidence pointed out a key role of sleep in declarative memory consolidation. Animal and human studies supported three main evidences: firstly, the amount of sleep—or the amount of a specific sleep stage - increased following learning or environmental enrichment, with a consequent increase in hippocampal and cortical plasticity. Secondly, sleep-or certain sleep stages-improved performance in certain memory and learning tasks. Finally, sleep deprivation impaired cognitive processing in different ways and, in healthy humans, it decreased the ability to induce long term potentiation (LTP) plasticity [30,31]. 
Sleep in mammals consists of a cyclic alternation between Rapid Eye Movement (REM) and Non-REM (NREM) sleep. REM sleep was characterized by a theta activity $(4-8 \mathrm{~Hz})$ that appear especially in the hippocampus, coupled to a gamma activity (30-120 Hz). NREM sleep is divided into light (N1 and N2) and deep sleep (N3, also called slow wave sleep-SWS). During the N2 stage of NREM sleep, there is a characteristic thalamo-cortical reactivation that displays sudden bursts of oscillatory brain activity between $12-15 \mathrm{~Hz}$ called sleep spindles. N3 NREM sleep is characterized by slow waves between $1-4 \mathrm{~Hz}$ and by slow oscillations (SO) of $<1 \mathrm{~Hz}$, which represent the slow wave activity (SWA) [32]. During this stage an interplay between the hippocampus and neocortex occurs [33]. Finally, in N3 NREM also appears hippocampal sharp-wave/ripples, which are intermittent patterns of highly synchronous spiking seen as high-frequency oscillations (120-200 Hz) [34-36]. It represents the reactivation of hippocampal memory representations and have been proposed as a cognitive biomarker for episodic memory [37]. Sleep spindles also occur during N3 sleep where their occurrence is often obscured by slow oscillations [38] (see Figure 1 for summarizing).

The interaction and the timing of these oscillations during NREM sleep will be critical for a correct communication between the hippocampus, neocortex and other structures. A precise timing will allow thalamic spindles to couple with the correct SO phase. The specific SO-spindle coupling will then facilitate synaptic plasticity and enhance consolidation, while a mistimed coupling will diminish memory formation. At the same time, hippocampal sharp-waves/ripples need to be timed to spindles, which will result in a spindle-ripple coupling. Therefore, the correct timing and characteristics of these waves will allow the reactivated hippocampal information (ripples) to be transmitted to the neocortex (SO), by way of the thalamus (spindles). This process will facilitate synaptic consolidations processes that will store the information as a long-term memory [39].

Finally, REM sleep is thought to process specifically emotional memories, given that it presents a distribution of theta activity within limbic structures. Furthermore, REM sleep seems to be also critical for working and spatial memory consolidation [40], with a characterized coupling between theta and gamma oscillations. From this point of view, REM would mediate the integration and recombination of memory traces previously consolidated during NREM sleep [41].

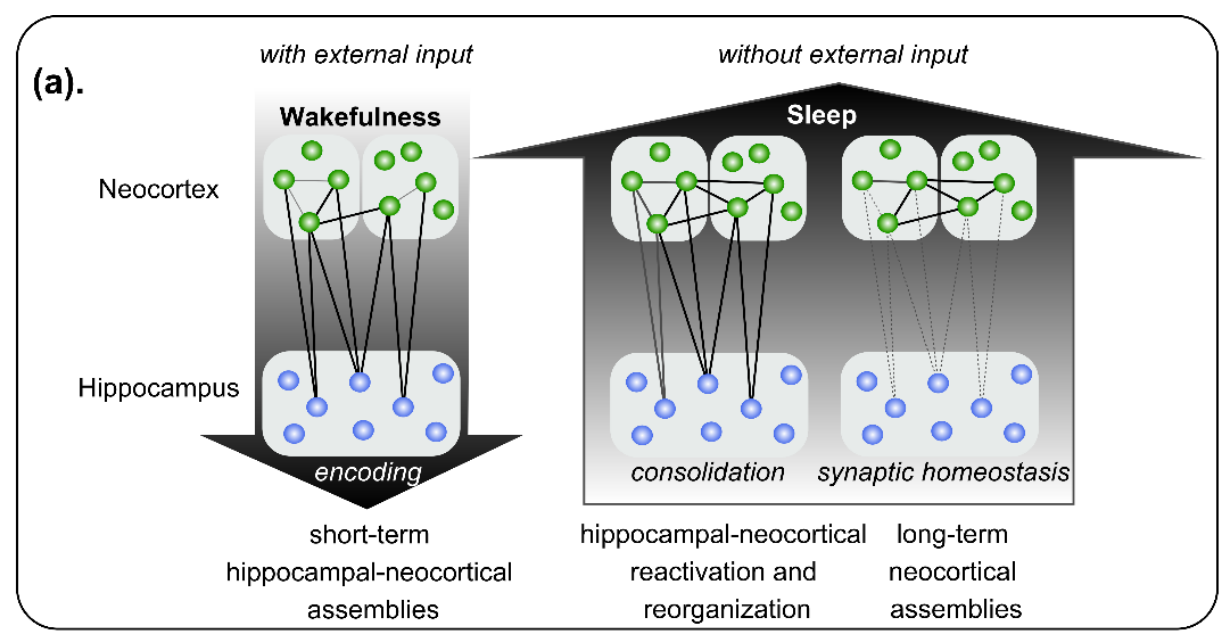

Figure 1. Cont. 


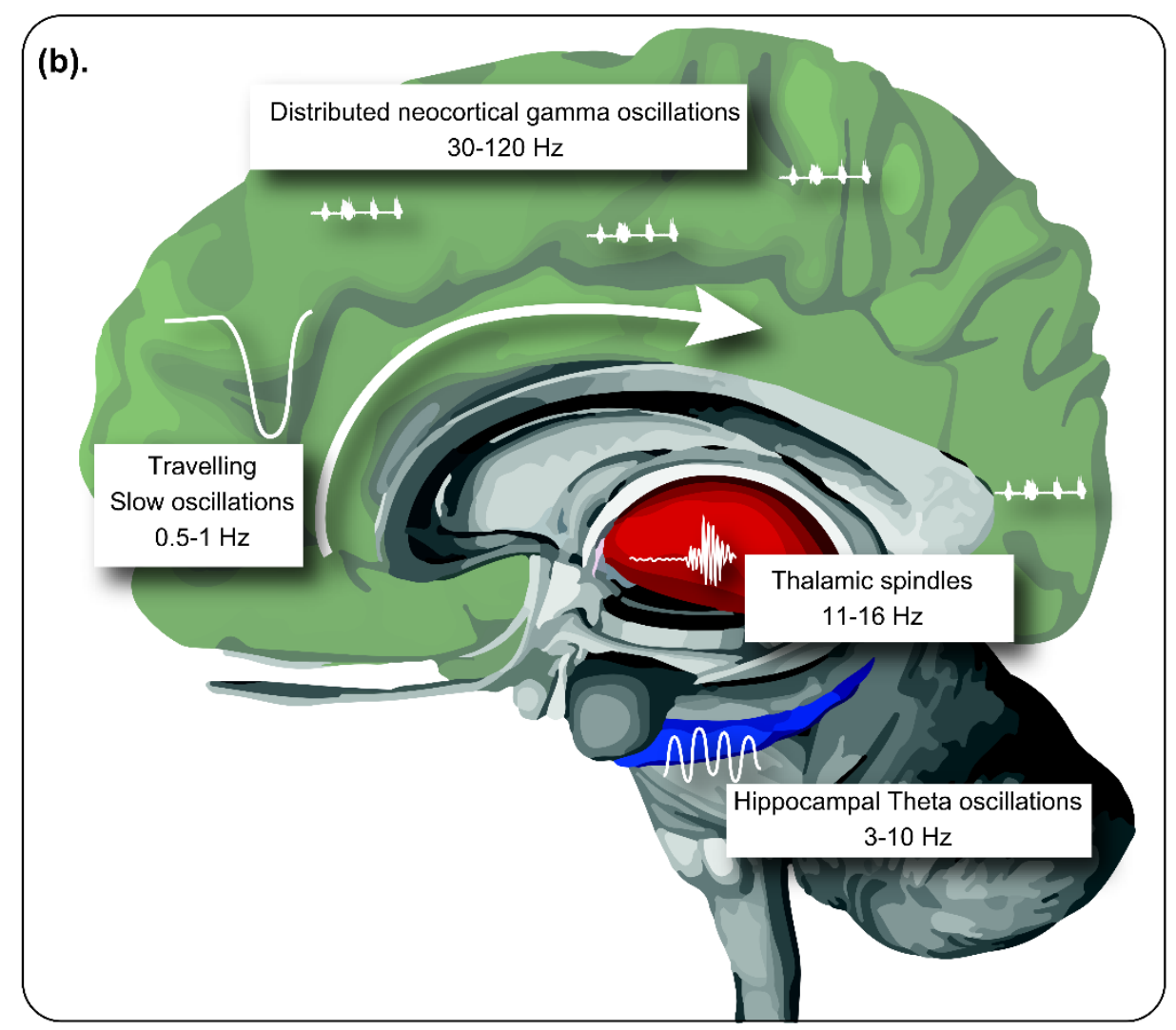

Figure 1. Role of sleep in memory consolidation. (a) During wakefulness, new memories are encoded by neuronal assemblies distributed within the neocortex and the hippocampal formation, integrating contextual information. During sleep, in absence of external inputs, memory reorganization is performed, reinforcing some neuronal assemblies by reactivation of the hippocampal-neocortical and thalamocortical circuits. Neural plasticity allows the consolidation of the stronger hippocampal-independent neocortical connections, together with the extinction of weak memory traces. (b) Neural oscillations hierarchically coupled allow memory processing during sleep. Slow oscillations propagate across cortical areas during Non-Rapid Eye Movement (NREM) sleep following a craneo-caudal direction, exhibiting upstates and downstates. During the downstates, neuronal rest is observed, while during upstates, highly synchronous discharges are observed, with replay of previous neuronal assemblies, coupled with sleep spindles originated in the thalamus. REM sleep is characterized by prominent theta waves in the hippocampal formation among other structures, coupled to gamma activity distributed within the neocortex. In this period, place-cells and grid cells exhibit a replay, allowing consolidation of contextual memory. Modified from Born and Wilhelm (2012) [42].

\section{Sleep and Memory in Sleep Disorders}

Sleep is important for the consolidation of memory, therefore disturbed sleep might consequently result in its impairment. Here we will briefly discuss insomnia and obstructive sleep apnea syndrome (OSA), the two most frequent sleep disorders that are especially associated with AD. Insomnia and OSA have been shown to affect sleep-related memory consolidation, by reducing sleep time, altering sleep architecture, and/or producing fragmented sleep [43].

\subsection{Insomnia}

Insomnia is defined a difficulty initiating or maintaining sleep, or early morning awakening associated with an impairment during daytime [43]. The European prevalence varied between 5.7\% to $19 \%$ [44] and its chronic form was related to a higher risk of cardiovascular diseases [45], depression [46], and cognitive impairment [47]. These risks were higher in patients that present short sleep duration, 
defined as less than $7 \mathrm{~h}$ of sleep per 24 -h. Furthermore, not only insomnia frequently accompanies other disorders, such as multiple sclerosis, epilepsy, and AD, but it could also aggravate their symptoms [48].

In addition to the volume changes in brain areas related to AD that we have mentioned in the introduction, patients with insomnia showed a decline in activity in the hypothalamus, thalamus, ascending reticular activating system, insular cortex, amygdala, hippocampus, and in the anterior cingulate and medial prefrontal cortices. A finding that suggested an overactivity of the arousal and a dysregulation of the emotion and cognitive systems in insomnia [49].

Insomnia patients also presented reduced amounts of both SWS and REM sleep, shifts in sleep stages, fast electroencephalographic frequencies and an increased frequency of brief awakenings and microarousals [48]. These changes, especially the reduction of SWS, caused an impairment in sleep-dependent declarative memory consolidation [50].

\subsection{Obstructive Sleep Apnea Syndrome}

OSA is a chronic sleep disorder with a prevalence that varies from $9 \%$ to $38 \%$ in the overall population [51] and that increases with age [52]. OSA is characterized by repetitive episodes of partial (hypopnea) or complete (apnea) upper airway obstruction leading to intermittent hypoxia, hypercarbia, and arousals throughout the night [53]. Patients showed cortical thinning in areas such as the precentral motor gyrus, the postcentral sensory gyrus and insular and temporal cortices [54], which presents neuronal damage and atrophy, leading to cognitive decline.

OSA patients could present a significant reduction of sleep efficiency, defined as the percentage of time spent asleep while in bed. They also showed increased waking after sleep onset and arousal index, leading to sleep fragmentation [55]. Furthermore, these patients displayed a different time course of SWA, a decreased sleep spindle index in both SWS and N2 [56] and slow spindle frequencies [57].

These alterations caused cognitive impairments in many domains, such as attention, memory, executive function, psychomotor function and visuospatial function [53], which can lead to mild cognitive impairment (MCI) and dementia in the aging population [58].

\section{Changes in Sleep and Memory in Normal Aging}

With aging, several changes in the patterns and architecture of sleep occurred, which were especially perceptible after the sixth decade of life. In humans, normal aging was associated with advanced sleep phase, as older adults frequently present a phase-shift, falling asleep early in the night and waking up early in the morning $[59,60]$. Total nocturnal sleep time showed a near linear decrease of 8-12 min per decade [59,61-63]. Furthermore, sleep efficiency also displayed a slow but continuous decline after the sixth decade [62].

Regarding sleep stages, NREM-REM sleep cycles were fewer and shorter. Aging was characterized by a linear decrease in the proportion of REM [60,61] and a reduced amount of deep NREM sleep, compensated with an increased duration of light NREM [47,64-66]. These changes in sleep architecture during adulthood have been confirmed by two different meta-analyses, one of which included subjects from childhood to old age [61,62]. Light sleep predominance made the sleep more fragile, which leads to an increase in the number of arousals and nocturnal awakenings, as well as a longer duration of wake time after sleep onset $[62,64]$. Therefore, sleep maintenance was altered, resulting in less consolidated sleep and an increase in fragmentation. This reduction in nocturnal sleep time and quality was accompanied by increased daytime sleepiness and daytime naps [59].

As for sleep's micro-architecture, SWA presented important reductions in amplitude, density and mean frequency in middle-aged adults, a deterioration that becomes especially prominent after 62 years old $[65,67,68]$. There was also a significant decline in N2 sleep spindle density with aging. Martin et al. (2013) found that age-related decline in density and amplitude of spindles was more prominent in anterior derivations, whereas duration decreased in the posterior derivations. Since each spindle characteristic seemed to present a distinct topographical pattern, they suggested that this topographical specificity could be a good biomarker to localize sleep's age-sensitive changes [69]. 
These alterations had consequences on affective and cognitive processing, including memory and learning. Aging was related to impaired memory and there was ample evidence suggesting that age-related memory impairment is mediated by sleep disruption. The duration of SWS predicted the accuracy of memory after sleep in older adults, when a paradigm of word learning is used [70]. Likewise, the degree of SWA impairment predicted a worse consolidation of memory during nighttime sleep, resulting in a greater number of forgetfulness the following day [71,72]. These changes in sleep organization and their contribution to cognitive processing could partially explain the cognitive decline seen in the elderly.

Furthermore, the prevalence of sleep disorders, especially insomnia and sleep disordered breathing, increased with aging. [73-75]. These disturbances could lead to cognitive impairment as seen by cross-sectional studies, where older adults with insomnia performed significantly worse on memory span, integration of visual and semantic dimensions, and executive functioning task [76-78].

\section{Sleep Disorders in Alzheimer's Disease}

Although sleep disturbances in AD patients were known for a long time, they used to be considered as just a consequence of the neurodegenerative process. However, current epidemiological studies showed that sleep disorders in AD patients go far beyond the physiological disturbances that occur in normal aging [10]. Early studies noted that sleep alterations were more prevalent amongst people with dementia than in the non-demented population [79]. This prevalence varied between $14-69 \%$ as was pointed out in a meta-analysis which included $5634 \mathrm{AD}$ patients [2]. Another multicenter-retrospective study in Japan with 684 AD patients found the prevalence to be $21.3 \%$ [80]. Other studies found over $60 \%$ of patients with $\mathrm{MCI}$ and $\mathrm{AD}$ had at least one clinical sleep disorder $[3,81]$ being insomnia and OSA the two most common. These discrepancies in prevalence could be related to the use of sleep questionnaires in many studies, as AD's cognitive impairment might make it difficult for patients to reliably inform sleep disturbances [82].

Recent studies highlighted a higher prevalence and severity of sleep alterations in patients with an early-onset form of the disease [2,3]. Furthermore, sleep problems were generally associated with a worse evolution, including the development of more severe cognitive and neuropsychiatric symptoms, with a diminished quality of life and also with a higher caregiver burden [83-85]. A meta-analysis conducted by Bubu and colleagues showed that sleep alteration is associated not only with cognitive impairment or symptomatic $\mathrm{AD}$, but also with changes in predictive biomarkers of people on the track to develop AD [10].

AD patients exhibited a significant alteration in the sleep/wake cycle, with an increase in the number of nighttime awakenings and a greater fragmentation of nocturnal sleep [79]. This nocturnal alteration was compensated with a much longer daytime sleep, consisting mainly of superficial sleep $[86,87]$.

As for the sleep's micro-architecture, nighttime sleep was also dominated by lighter sleep stages, with significant lesser percentages of SWS and REM sleep [87]. Importantly, when patients were separated by the disease severity, time spent on REM sleep tended to decrease as the disease progressed. Furthermore, a clear progression of the decrease in SWS was observed in parallel with cognitive decline $[88,89]$. We are going to analyze all these changes in depth in the next chapters.

\section{Possible Mechanisms by Which Sleep May Participate in the Pathogenesis of AD}

Dr. Alois Alzheimer described in 1907 the two major lesions found in the brains of AD patients, senile plaques and neurofibrillary tangles [90]. Senile plaques were mostly composed of beta-amyloid peptide $(A \beta)$, that had a strong tendency to aggregate and precipitate, forming the typical plaques of the disease [91]. On the other hand, neurofibrillary tangles were formed mainly by a cytoskeleton protein called tau in a hyperphosphorylated state (P-tau). When tau was hyperphosphorylated the cytoskeleton was disrupted causing irreparable damage to neurons, which begin an apoptotic pathway that will lead to neurodegeneration [92]. 


\subsection{Mechanisms Linking Sleep Respiratory Disorders with AD}

According to the meta-analysis conducted by Bubu and colleagues (2017) mentioned before, OSA was the sleep problem most associated with a higher risk of AD [10]. It was associated with sleep fragmentation, daytime sleepiness and significant cardiovascular and metabolic disturbances. Furthermore, OSA might be a risk factor for developing MCI and dementia in the aging population, as it induced cognitive dysfunction in many domains, such as attention, episodic memory, working memory, and executive function [93].

Both AD and OSA were chronic diseases with a high prevalence and it was known that there was some overlap between both. In a meta-analysis, Emamian et al. found that patients with AD had a five-times greater risk of developing OSA than age-matched controls without cognitive impairment [94] and, in this line, it has been described that approximately $50 \%$ of the patients with AD will develop OSA after the diagnosis [95]. Conversely, patients with OSA obtained worse results in neuropsychological tests of executive functions, such as attention and memory. Importantly, patients with OSA carrying at least one $\mathrm{APOE} \varepsilon 4$ allele, and therefore at risk of develop $\mathrm{AD}$, presented lower scores than those with OSA that do not carry the gene [93]. In this regard, a prospective study with cognitively normal older women showed that those with severe sleep breathing disorder had an increased risk of developing MCI or dementia at follow-up [47]. Moreover, OSA was associated with an earlier age-of-onset of $\mathrm{MCI}$ and of progression to $\mathrm{AD}[96]$. However, it seems that this risk had a gender difference, as a meta-analysis with almost twenty thousand subjects evidenced that sleep-related breathing disorders posed a significantly higher risk of cognitive decline for women than for man [97].

Recently, studies have seen an association between sleep-related breathing disorders and AD CSF biomarkers. While studying cognitively normal older adults, Osorio and colleagues (2014) found increases in CSF total-tau t(-tau), p-tau, and A $\beta$ in OSA subjects without ApoE4 allele. Conversely, they showed that treating OSA could improve AD biomarkers, as these subjects showed an increase in SWS and a decrease in the levels of CSF A $\beta$ when treated [98].

In addition to hypoxia, other factors such as progressive deterioration of sleep structure and sleep quality, as well as reduced brain flow, may contribute to cognitive impairment in patients with OSA and to an aggravation of $\mathrm{AD}$ in those patients with both pathologies [99].

\subsection{Sleep and Amyloid Burden}

So far, studies have shown a relationship between $A \beta$ levels and sleep, however, whether it is causal or not is still controversial. A recent study evaluating sleep disorders using a murine model of $\mathrm{AD}$, found that animals only presented sleep alterations after 6 months of age and that these alterations correlated to the performance on cognitive behavioral tests [100]. However, the authors did not measure $A \beta$ cerebral levels and their conclusion that there were no sleep disorders until amyloid pathology appeared was based on an estimated age of pathology appearance. Conversely, another murine model study showed that alterations in both EEG and sleep architecture appeared before the deposit of $A \beta$ in plaques, at $3-4$ months of age [6].

Neurons do not release $A \beta$ continuously but do so depending on their metabolic activity $[101,102]$. As CSF and blood metabolisms are generally regulated in a circadian manner, $\mathrm{A} \beta$ levels experiment cyclic fluctuations throughout the day $[103,104]$. Therefore, the concentration of this peptide in the brain's extracellular space increases during active periods and decreases with rest $[105,106]$. This was reinforced by Kang et al., which, using a murine model, demonstrated that levels of $A \beta$ in extracellular space correlated significantly with the time the animal was awake and that there was a negative correlation with sleep time, more accentuated for NREM sleep. In addition, sleep deprivation produced a clear increase of the previous day's levels and increased the formation of $A \beta$ plaques in the cerebral cortex [105].

In terms of human studies, sleep deprivation altered the levels of CSF A $\beta$ in cognitively normal people, which could be seen after a single night of complete sleep deprivation $[107,108]$. Furthermore, sleep quality was worse in cognitively normal older adults with amyloid deposits than in those without 
it [109]. Moreover, reduced and fragmented SWS were associated with increases in CSF A $\beta$ [110]. Of particular interest is a study by Mander at al. (2015) in cognitively normal older adults. In this study, the authors elaborated models to try to establish a causal relationship between $A \beta$ accumulation in medial prefrontal cortex, reduction of SWA, and alteration of hippocampus-dependent memory consolidation [111]. They found that the best model reflected an indirect influence of $A \beta$ deposits on the reduction of retentive memory, mediated by sleep. This result would imply a causal relation of $A \beta$ deposits on sleep, and of sleep on memory disorder [111]. In AD A $\beta$ accumulated in areas which generate NREM SWS [112], such as medial and lateral prefrontal cortex, posterior cingulate, and precuneus $[113,114]$. Interestingly, persons with higher cortical A $\beta$ presence had equivalently worse hippocampus-dependent memory [111,115-117]. These findings could lead to the conclusion that NREM sleep is the link between $\mathrm{A} \beta$ accumulation and $\mathrm{AD}^{\prime}$ s characteristic hippocampal-dependent memory loss.

Nevertheless, several authors pointed to a two-way relationship between sleep and amyloid pathology. Holtzman's group postulated that sleep disturbance and increased wakefulness would lead to increased production and decreased clearance of $A \beta$. Furthermore, once $A \beta$ is accumulated it results in more altered sleep, as evidenced in both mice and humans [118]. Meanwhile, Lucey et al. proposed that the initial appearance of $A \beta$ would hinder the generation of slow oscillations in NREM sleep. This deficit would, in turn, increase the production of wakefulness-dependent $A \beta$ and decrease sleep-dependent clearance, accelerating the deposit of $A \beta$ and thus exacerbating the pathological cascade of AD [104,119].

\subsection{Sleep and Tau Pathology}

Very recent studies explored the relationship between tau pathology and different aspects of sleep. In the aforementioned work by Lucey et al. (2019), not only A $\beta$, but also tau pathology correlated to sleep disturbances in cognitively normal people and in those with MCI. The authors analyzed SWA in NREM sleep and showed an inverse relationship between AD pathology and SWA, especially in the lower range of the studied frequencies $(1-2 \mathrm{~Hz})$. Moreover, they found a stronger relationship between tau and SWA than between $A \beta$ and SWA, leading them to conclude that tauopathy, rather than $A \beta$, correlates with sleep disturbances in asymptomatic or mildly symptomatic AD [119]. In another study by Kam et al. (2019), NREM sleep correlated with the amount of CSF A $\beta$, p-tau, and t-tau. Interestingly, of the three, $\mathrm{t}$-tau was the one that most significantly associated with sleep spindle density, after adjusting for age, sex and ApoE4. Moreover, spindle duration, count, and density of fast spindles also correlated negatively with t-tau levels [120]. Lastly, Holth et al. (2019) found that the sleep-wake cycle and sleep deprivation influenced the amount of tau in interstitial fluid and CSF, both in experimental animals and in humans. Furthermore, they provided direct evidence that sleep disruption promoted the release and propagation of pathological tau aggregates in mice and that sleep deprivation in humans leads to an increase of more than 50\% in CSF tau [121].

Tauopathy in AD seemed to begin very early in the locus coeruleus, where p-tau appeared decades before the first signs of cognitive impairment and, from there, it spread through axons to other memory related areas such as the entorhinal cortex and hippocampus [122]. With that in mind, Zhu et al. (2018) examined the effects of chronic sleep disruption on tauopathy in the locus coeruleus and hippocampus of transgenic mice that expressed a human tau protein with a mutation linked to AD. This study demonstrated that sleep disruption in early adulthood accelerated the deterioration of motor performance and increased neuronal loss in the locus coeruleus. Moreover, they found elevated levels of p-tau oligomers, which could still be observed 6 months after the sleep deprivation period, indicating that disturbances in this area were long maintained [123]. Other murine studies reinforce these results by evidencing that chronic sleep restriction may increase tau levels and that it may also impair hippocampus-dependent memory [124,125]. 
Lastly, it is recently proposed that an impairment in the SO-sleep spindle coupling might be a predictor of higher tau burden in the medial temporal lobe, but not of $A \beta$ burden, while a diminished amplitude of $<1 \mathrm{~Hz}$ SWA may be a predictor of $A \beta$ burden [126].

In summary, there were evidences to support that sleep abnormalities increase both $A \beta$ and tau and also that these pathological proteins may induce sleep disturbances. Therefore, it is important to emphasize the bidirectional role or positive feedback that occurs between these two processes.

\subsection{Sleep and Glymphatic System}

The transport of small metabolites and other molecules within the interstitial space determined the clearance of potentially neurotoxic peptides, such as A $\beta$ and tau. CSF exchanged substances with the interstitial fluid, thus eliminating the products of cellular activity. It was likely that sleep, using this pathway, had the important function of removing multiple potentially toxic waste substances derived from neural metabolism, which may explain the restorative capacity of sleep [127].

Nevertheless, in the last decade, a new pathway for solute clearance has been proposed, in an attempt to better explain the relationship between sleep and the deposit of $A \beta$ and other substances. Iliff's group was the first to describe, in mice, a paravascular pathway that allowed the clearance of interstitial fluid through paravenous drainage [128]. In the central nervous system, vessels were surrounded by astrocyte podocytes that express the water channel aquaporin-4. Mice lacking AQP4 had reduced CSF influx through this paravascular system and a reduction of interstitial A $\beta$ clearance. As a result of its analogy with the lymphatic system, this mechanism was called the "glymphatic system".

The glymphatic activity seemed to be an important feature of the sleeping brain, rather than of the awake brain. Therefore, these changes in the paravascular flow could underlie the circadian fluctuations in extracellular and CSF A $\beta$ levels observed in both rodents and humans [129]. In a study comparing awake mice with mice in states of physiological sleep or sleep induced by anesthesia, Xie and colleagues [130] found that $A \beta$ was eliminated more efficiently (at twice the speed) during physiological sleep or anesthesia, than during wakefulness. Additionally, they evidenced that in the awake state there was a reduction in the cerebral interstitial space. These authors hypothesized that the contraction of the interstitial space in wakefulness increases the resistance of cerebral tissue to the flow of interstitial fluid and to entry of CSF. Furthermore, these alterations might have an adrenergic mechanism, as the administration of adrenergic antagonists in awake mice induced an increase of the affluence of tracers into the CSF and also of the volume of the interstitium, at levels comparable to those of sleep or anesthesia. Nevertheless, glymphatic activity seemed to decrease abruptly with aging, as evidenced by an $80-90 \%$ reduction of the glymphatic function in old mice [131], although more evidences and experiments are needed to extrapolate to humans.

Based on these results, many researchers are focusing their attention on this novel mechanism linking sleep, metabolite clearance and the development of AD [127,129,132-134], even though it has received contrary and critical opinions [135].

\section{Sleep-Related Proposed Biomarkers in AD}

Currently, evaluation of CSF A $\beta$ and tau levels are AD's gold standard biomarkers. However, this requires a lumbar puncture which is not only an unpleasant procedure, but it is also invasive. For this reason, it is important to investigate new reliable and noninvasive biomarkers, and some specific sleep abnormalities could be good candidates.

As mentioned earlier, sleep stages are characterized by specific oscillatory activities which are relevant to memory processing, neuronal rest and maintenance of homeostasis. Thus, in the search of useful new biomarkers, it is interesting to analyze the changes that appear in certain oscillatory patterns and their relationship with gold standard biomarkers. 


\subsection{General EEG Features}

Early studies in AD patients demonstrated a slowing of the awake and REM sleep occipital EEG (from $9.40 \mathrm{~Hz}$ to $6.40 \mathrm{~Hz}$ ), the occurrence of paroxysmal sharp waves in quiet wakefulness or during sleep and "poorly formed or absent" spindle activity [88]. In general, the reduction of deep sleep, the increase of awakenings and the progressive slowing of EEG activity were seen in normal aging but were remarkably accentuated in $\mathrm{AD}$ patients.

\subsection{SWA in NREM}

Studies in healthy elderly adults found that both diminished SWA and SWA disruption were associated with elevated CSF A $\beta[99,110,136]$. Likewise, Mander and colleagues (2015) observed that NREM sleep SO correlated with the deposits of $A \beta$. Given that the association between amyloid pathology and NREM sleep disturbances occurred not only in MCI and AD, but also in older subjects in the preclinical phase, the authors proposed that a reduction of $<1 \mathrm{~Hz}$ slow oscillatory activity index in NREM sleep may constitute a new biomarker of preclinical AD [111]. Specifically, diminished N3 slow wave oscillations were associated with elevated CSF A $\beta 42[99,110]$, and slow wave activity disruption during polysomnogram induced increases of CSF A $\beta 40$ [136]. The aforementioned work by Osorio and colleagues (2014) provided useful objective measures in the search for biomarkers by combining polysomnography and CSF measures, studying cognitively normal elderly subjects [98]. They found a significant inverse correlation between CSF A $\beta 42$ levels, SWS duration and other SWS parameters. In particular, total SWA in the frontal electrodes was the best predictor of reduced CSF A $\beta 42$ levels when controlling for age and ApoE status. Remarkably, they did not find correlation between CSF A $\beta 42$ with total sleep time or time in N1, N2, or REM sleep. Therefore, reduced and fragmented SWS correlated with higher levels of CSF A $\beta_{42}$. On the light of their findings, the authors suggest that disturbed deep sleep might have a causal relationship to the pathogenesis because of an increase in soluble $A \beta$ levels prior to amyloid deposition [110].

On the other hand, Lucey and colleagues found a stronger inverse relationship between SWA, especially for frequencies of $1-2 \mathrm{~Hz}$, and tau rather than $A \beta$ in asymptomatic or mildly symptomatic AD. So, the authors proposed that SWA reduction in NREM may be an early biomarker of AD and that it could also serve to monitor the progression of AD pathology and the response to treatment, given that its measurement does not require invasive techniques [104].

\subsection{Other Possible Biomarkers}

A very recent research, performed on cognitively normal elderly individuals, found a significant negative correlation between spindle density in N2 sleep and CSF $t$-tau, $p$-tau, and A $\beta$. This correlation was especially strong with $\mathrm{t}$-tau as well as with the ratio of $\mathrm{t}$-tau/A $\beta$. Nevertheless, CSF tau measures did not correlate with total sleep time nor with sleep quality [120]. So, spindle density in N2 could be another candidate as AD biomarker.

On the other hand, while SO measurements correlated very well with A $\beta$, it was the SO-Spindle coupling that predicted the greatest accumulation of tau specifically in the medial temporal lobe [126]. Considering that coupling of SO-spindles was involved in sleep-dependent hippocampal memory processing [137], was not surprising its contribution to AD-related cognitive decline.

In studies with transgenic mice carrying human amyloid precursor protein (h-APP), although no differences were found in net theta power nor gamma power, theta-gamma coupling was found to be dramatically reduced [138]. Other studies have evidenced further gamma coupling alterations [139]. However, to date, no studies have described similar data in human REM sleep, when theta and theta-gamma coupling were predominant [140]. It would be worthwhile to evaluate these issues in humans, seen as REM sleep disruption forecasted worse Mini-Mental State Examination scores in MCI and AD patients [141-143]. 
Finally, molecules implicated in the glymphatic system could be another line of research of future sleep-related biomarkers in AD pathology (Table 1).

Table 1. Current evidence of possible sleep biomarkers and their association with gold standard Alzheimer's disease (AD) biomarkers.

\begin{tabular}{|c|c|c|c|}
\hline Oscillatory Parameter & $\mathrm{A} \beta$ Burden & Tau Pathology & AD-Related Localization \\
\hline NREM SWA $(<1 \mathrm{~Hz})$ & $\checkmark$ & & $\begin{array}{c}\text { Prefrontal Cortex } \\
\text { Posterior cingulate } \\
\text { Precuneus } \\
\text { CSF }\end{array}$ \\
\hline NREM SWA (1-4 Hz) & & $\checkmark$ & $\begin{array}{c}\text { Entorhinal } \\
\text { Parahippocampal Orbital frontal } \\
\text { Precuneus } \\
\text { Inferior parietal } \\
\text { Inferior temporal }\end{array}$ \\
\hline Spindles & $\checkmark$ & $\checkmark$ & CSF \\
\hline SO-Spindle coupling & & $\checkmark$ & Medial temporal lobe \\
\hline
\end{tabular}

\section{Could Sleep Oscillatory Activities be Good Biomarkers for AD?}

The criteria for establishing a good biomarker for the diagnosis of AD include: to reflect a pathophysiological process of the disease; to display high sensitivity and specificity for $\mathrm{AD}$; to react upon pharmacological intervention; and to be reproducible, noninvasive, inexpensive, and rapid [144]. Therefore, specific sleep alterations might be good candidates since they reflect the pathological brain processes related to $\mathrm{AD}$, that is, they correlate to $\mathrm{A} \beta$ and tau levels. It is important to highlight that a good biomarker should correlate with the two main pathological signatures of $A D$ independently, $A \beta$ and p-tau, and that is the case with these sleep alterations. Furthermore, their evaluation is reproducible, noninvasive, and cost-effective, as the development of portable machines makes polysomnography a non-complicated technique that can be performed wherever the patient is.

Nevertheless, their sensitivity and specificity for AD has yet to be analyzed and also their changes related to a pharmacological intervention. The most recent studies point to the higher utility of studying specific oscillatory patterns rather than general data or even visual analysis of the sleep microarchitecture. More studies are needed to evaluate the response of sleep-related possible biomarkers to such an intervention, as current medications used to aid sleep are not designed to improve these specific parameters.

Moreover, many neurologic and psychiatric diseases present sleep disorders. Therefore, in order to reach higher specificity, it is key to detect changes in the microarchitecture of sleep oscillations that only occur in AD. Such details could be better controlled in animal models of AD and further validated in human studies. In addition, given AD presents higher prevalence in women, the design of sleep studies should consider gender differences in sleep parameters.

Should these obstacles be overcome, sleep-related biomarkers could have a promising role as a tool to support the diagnosis of $\mathrm{AD}$ in patients with cognitive decline, as well as to evaluate disease progression, as they seem to correlate well with disease severity and cognitive decline.

\section{Conclusions}

Sleep alterations occur both in normal aging and in $\mathrm{AD}$ and they include a decrease in total sleep time, REM sleep, and deep NREM sleep (SWS), and an increase in sleep fragmentation and in the time spent in light NREM phases. However, some specific oscillatory patterns (reduction of SWA and of spindle density and impairment in the slow oscillation-sleep spindle coupling as well as theta-gamma coupling) are associated with an increase in biomarkers of AD neuropathology. Evidence supports a bidirectional relationship between sleep abnormalities and $\mathrm{A} \beta$ and tau burden, meaning that sleep 
disruption might be both a cause and a consequence of AD. Nevertheless, much needs still to be learned about these links, especially after the glymphatic system has been described as a possible new pathway linking sleep and AD. Lastly, specific oscillatory patterns linked to sleep disruption seem to be good candidates as biomarkers to help in the early diagnosis of the disease and to track its evolution, although more studies are still needed before considering them as useful biomarkers in clinical practice. See Figure 2 for a schematic rendition summarizing the main features relating AD and sleep disorders.

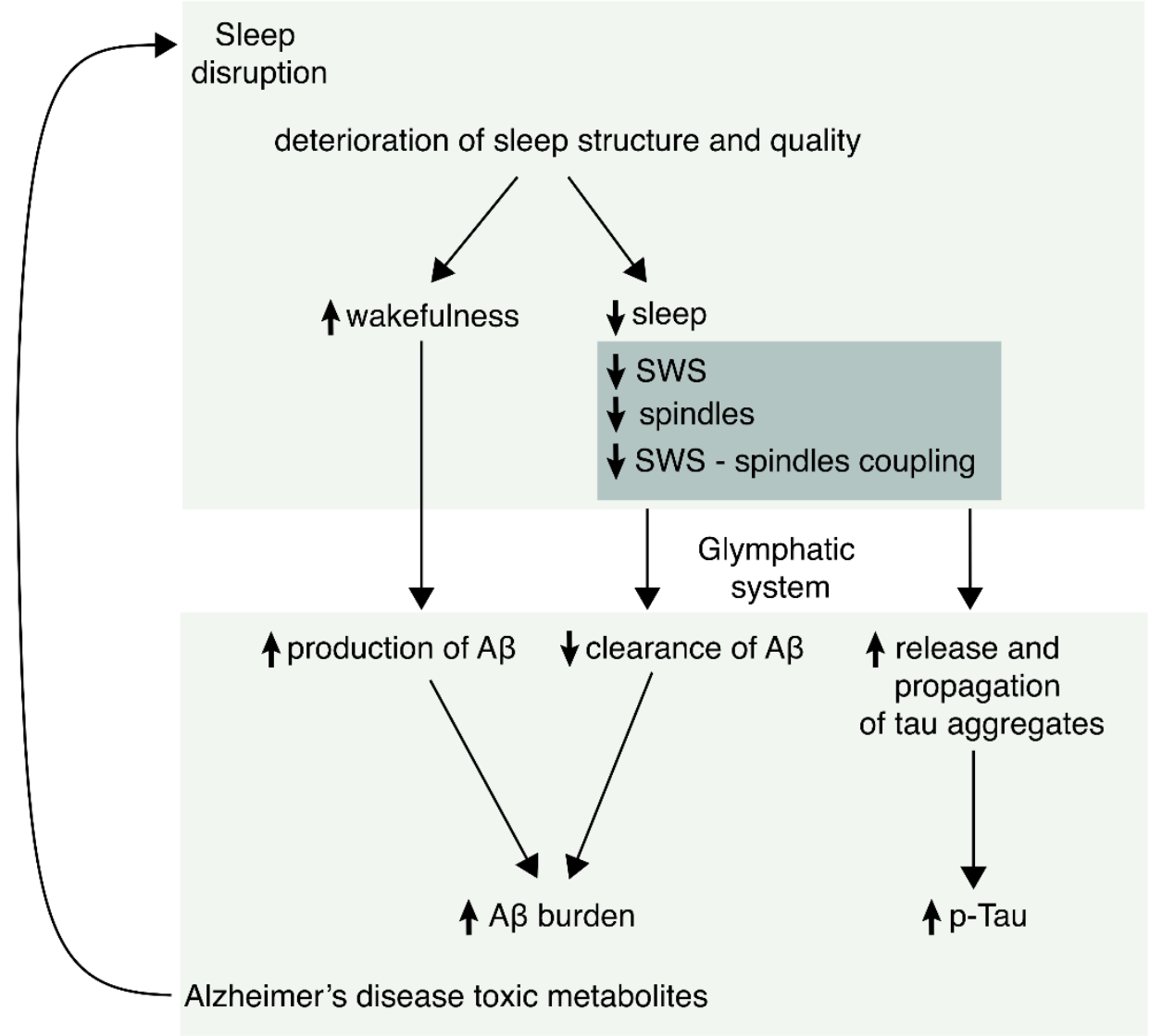

Figure 2. Schematic rendition summarizing the possible sleep biomarkers in AD. Experimental evidence suggests that sleep disorders appear early in AD. Sleep abnormalities induce more formation of pathological tau and beta-amyloid peptide $(\mathrm{A} \beta)$. Likewise, both $\mathrm{A} \beta$ and P-tau induce sleep disorders, generating a positive feedback process.

Author Contributions: All authors have contributed to the writing, formatting, and editing of the manuscript. All authors have read and agreed to the published version of the manuscript.

Funding: This research received no external funding.

Conflicts of Interest: The authors declare no conflict of interest.

\section{References}

1. Bature, F.; Guinn, B.A.; Pang, D.; Pappas, Y. Signs and symptoms preceding the diagnosis of Alzheimer's disease: A systematic scoping review of literature from 1937 to 2016. BMJ Open 2017, 7, e015746. [CrossRef] [PubMed]

2. Zhao, Q.F.; Tan, L.; Wang, H.F.; Jiang, T.; Tan, M.S.; Tan, L.; Xu, W.; Li, J.Q.; Wang, J.; Lai, T.J.; et al. The prevalence of neuropsychiatric symptoms in Alzheimer's disease: Systematic review and meta-analysis. J. Affect. Disord. 2016, 190, 264-271. [CrossRef] [PubMed] 
3. Guarnieri, B.; Adorni, F.; Musicco, M.; Appollonio, I.; Bonanni, E.; Caffarra, P.; Caltagirone, C.; Cerroni, G.; Concari, L.; Cosentino, F.I.I.; et al. Prevalence of Sleep Disturbances in Mild Cognitive Impairment and Dementing Disorders: A Multicenter Italian Clinical Cross-Sectional Study on 431 Patients. Dement. Geriatr. Cogn. Disord. 2012, 33, 50-58. [CrossRef] [PubMed]

4. Gehrman, P.; Gooneratne, N.S.; Brewster, G.S.; Richards, K.C.; Karlawish, J. Impact of Alzheimer disease patients' sleep disturbances on their caregivers. Geriatr. Nurs. (Minneap). 2018, 39, 60-65. [CrossRef]

5. Baillon, S.; Gasper, A.; Wilson-Morkeh, F.; Pritchard, M.; Jesu, A.; Velayudhan, L. Prevalence and Severity of Neuropsychiatric Symptoms in Early- Versus Late-Onset Alzheimer's Disease. Am. J. Alzheimer's Dis. Other Dementias ß 2019, 34, 433-438. [CrossRef]

6. Zhang, F.; Zhong, R.; Li, S.; Fu, Z.; Wang, R.; Wang, T.; Huang, Z.; Le, W. Alteration in sleep architecture and electroencephalogram as an early sign of Alzheimer's disease preceding the disease pathology and cognitive decline. Alzheimer's Dement. 2019, 15, 590-597. [CrossRef]

7. Potvin, O.; Lorrain, D.; Forget, H.; Dubé, M.; Grenier, S.; Préville, M.; Hudon, C. Sleep quality and 1-year incident cognitive impairment in community-dwelling older adults. Sleep 2012, 35, 491-499. [CrossRef]

8. Lim, A.S.; Kowgier, M.; Yu, L.; Buchman, A.S.; Bennett, D.A. Sleep Fragmentation and the Risk of Incident Alzheimer's Disease and Cognitive Decline in Older Persons. Sleep 2013, 36, 1027-1032. [CrossRef]

9. Benedict, C.; Byberg, L.; Cedernaes, J.; Hogenkamp, P.S.; Giedratis, V.; Kilander, L.; Lind, L.; Lannfelt, L.; Schiöth, H.B. Self-reported sleep disturbance is associated with Alzheimer's disease risk in men. Alzheimers Dement. 2015, 11, 1090-1097. [CrossRef]

10. Bubu, O.M.; Brannick, M.; Mortimer, J.; Umasabor-Bubu, O.; Sebastião, Y.V.; Wen, Y.; Schwartz, S.; Borenstein, A.R.; Wu, Y.; Morgan, D.; et al. Sleep, Cognitive impairment, and Alzheimer's disease: A Systematic Review and Meta-Analysis. Sleep 2017, 40, zsw032. [CrossRef]

11. Shireen, S.; Ingemar, K.; Lena, J.; Johan, S.; Linnea, S.; Hui-Xin, W.; Boo, J.; Laura, F.; Hilkka, S.; Alina, S.; et al. Sleep disturbances and dementia risk: A multicenter study. Alzheimers Dement. 2018, 14, 1235-1242.

12. Li, S.; Tian, J.; Bauer, A.; Huang, R.; Wen, H.; Li, M.; Wang, T.; Xia, L.; Jiang, G. Reduced integrity of right lateralized white matter in patients with primary insomnia: A diffusion-tensor imaging study. Radiology 2016, 280, 520-528. [CrossRef] [PubMed]

13. Koo, D.L.; Shin, J.H.; Lim, J.S.; Seong, J.K.; Joo, E.Y. Changes in subcortical shape and cognitive function in patients with chronic insomnia. Sleep Med. 2017, 35, 23-26. [CrossRef] [PubMed]

14. Alperin, N.; Wiltshire, J.; Lee, S.H.; Ramos, A.R.; Hernandez-Cardenache, R.; Rundek, T.; Curiel Cid, R.; Loewenstein, D. Effect of sleep quality on amnestic mild cognitive impairment vulnerable brain regions in cognitively normal elderly individuals. Sleep 2018, 42, 1-10. [CrossRef]

15. Altena, E.; Vrenken, H.; Van Der Werf, Y.D.; van den Heuvel, O.A.; Van Someren, E.J.W. Reduced orbitofrontal and parietal gray matter in chronic insomnia: A voxel-based morphometric study. Biol. Psychiatry 2010, 67, 182-185. [CrossRef] [PubMed]

16. Meng, L.; Jianhao, Y.; Shumei, L.; Tianyue, W.; Hua, W.; Yi, Y.; Shishun, F.; Luxian, Z.; Junzhang, T.; Guihua, J. Altered gray matter volume in primary insomnia patients: A DARTEL-VBM study. Brain Imaging Behav. 2018, 12, 1759-1767. [CrossRef]

17. Winkelman, J.W.; Plante, D.T.; Schoerning, L.; Benson, K.; Buxton, O.M.; O'Connor, S.P.; Jensen, J.E.; Renshaw, P.F.; Gonenc, A. Increased rostral anterior cingulate cortex volume in chronic primary insomnia. Sleep 2013, 36, 991-998. [CrossRef]

18. Riemann, D.; Voderholzer, U.; Spiegelhalder, K.; Hornyak, M.; Buysse, D.J.; Nissen, C.; Hennig, J.; Perlis, M.L.; van Elst, L.T.; Feige, B. Chronic insomnia and MRI-measured hippocampal volumes: A pilot study. Sleep 2007, 30, 955-958. [CrossRef]

19. Yeon, J.E.; Hosung, K.; Sooyeon, S.; Bong, H.S. Hippocampal Substructural Vulnerability to Sleep Disturbance and Cognitive Impairment in Patients with Chronic Primary Insomnia: Magnetic Resonance Imaging Morphometry. Sleep 2014, 37, 1189-1198. [CrossRef]

20. Sexton, C.E.; Storsve, A.B.; Walhovd, K.B.; Johansen-Berg, H.; Fjell, A.M. Poor sleep quality is associated with increased cortical atrophy in community-dwelling adults. Neurology 2014, 83, 967-973. [CrossRef]

21. Grau-Rivera, O.; Operto, G.; Falcón, C.; Sánchez-Benavides, G.; Cacciaglia, R.; Brugulat-Serrat, A.; Gramunt, N.; Salvadó, G.; Suárez-Calvet, M.; Minguillon, C.; et al. Association between insomnia and cognitive performance, gray matter volume, and white matter microstructure in cognitively unimpaired adults. Alzheimers Res. Ther. 2020, 12, 4-18. [CrossRef] [PubMed] 
22. Wennberg, A.M.V.; Wu, M.N.; Rosenberg, P.B.; Spira, A.P. Sleep Disturbance, Cognitive Decline, and Dementia: A Review. Semin. Neurol. 2017, 37, 395-406. [PubMed]

23. McDade, E.; Bateman, R.J. Stop Alzheimer's before it starts. Nature 2017, 547, 153-155. [CrossRef] [PubMed]

24. Frank, M.G. Erasing synapses in sleep: Is it time to be SHY? Neural Plast. 2012, 2012, 264378-264393. [CrossRef]

25. Peigneux, P.; Smith, C. Memory Processing in Relation to Sleep. In Principles and Practice of Sleep Medicine, 5th ed.; Kryger, M., Roth, T., Dement, W., Eds.; Elsevier Saunders: St Louis, MO, USA, 2010; Chapter 29; p. 335347, ISBN 9781416066453.

26. Godbolt, A.K.; Cipolotti, L.; Watt, H.; Fox, N.C.; Janssen, J.C.; Rossor, M.N. The natural history of Alzheimer disease: A longitudinal presymptomatic and symptomatic study of a familial cohort. Arch. Neurol. 2004, 61, 1743-1748. [CrossRef]

27. Molinuevo, J.L.; Valls-Pedret, C.; Rami, L. From mild cognitive impairment to prodromal Alzheimer disease: A nosological evolution. Eur. Geriatr. Med. 2010, 73, 384-385. [CrossRef]

28. Howieson, D.B. Cognitive decline in presymptomatic Alzheimer Disease. JAMA Neurol. 2016, 73, $384-385$. [CrossRef]

29. Rasch, B.; Born, J. About Sleep's Role in Memory. Physiol Rev. 2013, 93, 681-766. [CrossRef]

30. Chambers, A.M. The role of sleep in cognitive processing: Focusing on memory consolidation. Wiley Interdiscip. Rev. Cogn. Sci. 2017, 8, e1433. [CrossRef]

31. Kuhn, M.; Wolf, E.; Maier, J.G.; Mainberger, F.; Feige, B.; Schmid, H.; Bürklin, J.; Maywald, S.; Mall, V.; Jung, N.H.; et al. Sleep recalibrates homeostatic and associative synaptic plasticity in the human cortex. Nat. Commun. 2016, 7, 12455-12464. [CrossRef]

32. Staresina, B.P.; Bergmann, T.O.; Bonnefond, M.; Van Der Meij, R.; Jensen, O.; Deuker, L.; Elger, C.E.; Axmacher, N.; Fell, J. Hierarchical nesting of slow oscillations, spindles and ripples in the human hippocampus during sleep. Nat. Neurosci. 2015, 18, 1679-1686. [CrossRef] [PubMed]

33. Sirota, A.; Buzsáki, G. Interaction between neocortical and hippocampal networks via slow oscillations. Thalamus Relat. Syst. 2005, 3, 245-259. [CrossRef] [PubMed]

34. Buzsáki, G.; Horváth, Z.; Urioste, R.; Hetke, J.; Wise, K. High-frequency network oscillation in the hippocampus. Science 1992, 256, 1025-1027. [CrossRef] [PubMed]

35. Ylinen, A.; Bragin, A.; Nadasdy, Z.; Jando, G.; Szabo, I.; Sik, A.; Buzsaki, G. Sharp wave-associated high-frequency oscillation $(200 \mathrm{hz})$ in the intact hippocampus: Network and intracellular mechanisms. J. Neurosci. 1995, 15, 30-46. [CrossRef]

36. Maier, N.; Nimmrich, V.; Draguhn, A. Cellular and network mechanisms underlying spontaneous sharp wave-ripple complexes in mouse hippocampal slices. J. Physiol. 2003, 550, 873-887. [CrossRef]

37. Davidson, T.J.; Kloosterman, F.; Wilson, M.A. Hippocampal Replay of Extended Experience. Neuron 2009, 63, 497-507. [CrossRef]

38. Cox, R.; Schapiro, A.C.; Manoach, D.S.; Stickgold, R. Individual Differences in Frequency and Topography of Slow and Fast Sleep Spindles. Front. Hum. Neurosci. 2017, 11, 433. [CrossRef]

39. Klinzing, J.G.; Niethard, N.; Born, J. Mechanisms of systems memory consolidation during sleep. Nat. Neurosci. 2019, 22, 1598-1610.

40. Bandarabadi, M.; Boyce, R.; Herrera, C.G.; Bassetti, C.; Williams, S.; Schindler, K.; Adamantidis, A. Dynamical modulation of theta-gamma coupling during REM sleep. Sleep 2019, 42, 182. [CrossRef]

41. Hutchison, I.C.; Rathore, S. The role of REM sleep theta activity in emotional memory. Front. Psychol. 2015, 6, 1-15. [CrossRef]

42. Born, J.; Wilhelm, I. System consolidation of memory during sleep. Psychol Res. 2012, 76, 192-203. [CrossRef] [PubMed]

43. Cellini, N. Memory consolidation in sleep disorders. Sleep Med. Rev. 2017, 35, 101-112. [CrossRef] [PubMed]

44. Riemann, D.; Baglioni, C.; Bassetti, C.; Bjorvatn, B.; Dolenc Groselj, L.; Ellis, J.G.; Espie, C.A.; Garcia-Borreguero, D.; Gjerstad, M.; Gonçalves, M.; et al. European guideline for the diagnosis and treatment of insomnia. J. Sleep Res. 2017, 26, 675-700. [CrossRef] [PubMed]

45. Fernandez-Mendoza, J.; Vgontzas, A.N.; Liao, D.; Shaffer, M.L.; Vela-Bueno, A.; Basta, M.; Bixler, E.O. Insomnia with objective short sleep duration and incident hypertension: The Penn State Cohort. Hypertension 2012, 60, 929-935. [CrossRef] [PubMed] 
46. Baglioni, C.; Battagliese, G.; Feige, B.; Spiegelhalder, K.; Nissen, C.; Voderholzer, U.; Lombardo, C.; Riemann, D. Insomnia as a predictor of depression: A meta-analytic evaluation of longitudinal epidemiological studies. J. Affect. Disord. 2011, 135, 10-19. [CrossRef]

47. Yaffe, K.; Falvey, C.M.; Hoang, T. Connections between sleep and cognition in older adults. Lancet Neurol. 2014, 10, 1017-1028. [CrossRef]

48. Riemann, D.; Nissen, C.; Palagini, L.; Otte, A.; Perlis, M.L.; Spiegelhalder, K. The neurobiology investigation and treatment of chronic insomnia. Lancet Neurol. 2015, 14, 547-558. [CrossRef]

49. Nofzinger, E.A.; Buysse, D.J.; Germain, A.; Price, J.C.; Miewald, J.M.; Kupfer, D.J. Functional neuroimaging evidence for hyperarousal in insomnia. Am. J. Psychiatry 2004, 161, 2126-2128. [CrossRef]

50. Backhaus, J.; Junghanns, K.; Born, J.; Hohaus, K.; Faasch, K.; Hohagen, F. Impaired Declarative Memory Consolidation during Sleep in Patients with Primary Insomnia: Influence of Sleep Architecture and Nocturnal Cortisol Release. Biol. Psychiatry 2006, 60, 1324-1330. [CrossRef]

51. Senaratna, C.V.; Perret, J.L.; Lodge, C.J.; Lowe, A.J.; Campbell, B.E.; Matheson, M.C.; Hamilton, G.S.; Dharmage, S.C. Prevalence of obstructive sleep apnea in the general population: A systematic review. Sleep Med. Rev. 2017, 34, 70-81. [CrossRef]

52. Rosenzweig, I.; Glasser, M.; Polsek, D.; Leschziner, G.D.; Williams, S.C.; Morrell, M.J. Sleep apnoea and the brain: A complex relationship. Lancet Respir Med. 2015, 3, 404-414. [CrossRef]

53. Olaithe, M.; Bucks, R.S.; Hillma, D.R.; Eastwood, P.R. Cognitive deficits in obstructive sleep apnea: Insights from a meta-review and comparison with deficits observed in COPD; insomnia; and sleep deprivation. Sleep Med. Rev. 2018, 38, 39-49. [CrossRef] [PubMed]

54. Macey, P.M.; Haris, N.; Kumar, R.; Thomas, M.A.; Woo, M.A.; Harper, R.M. Obstructive sleep apnea and cortical thickness in females and males. PLoS ONE 2018, 13, e0193854. [CrossRef] [PubMed]

55. Jones, S.G.; Riedner, B.A.; Smith, R.F.; Ferrarelli, F.; Tononi, G.; Davidson, R.J.; Benca, R.M. Regional reductions in sleep electroencephalography power in obstructive sleep apnea: A high-density EEG study. Sleep 2014, 37, 399-407. [CrossRef] [PubMed]

56. Ondze, B.; Espa, F.; Dauvilliers, Y.; Billiard, M.; Besset, A. Sleep architecture; slow wave activity and sleep spindles in mild sleep disordered breathing. Clin. Neurophysiol. 2003, 114, 867-874. [CrossRef]

57. Himanen, S.L.; Virkkala, J.; Huupponen, E.; Hasan, J. Spindle frequency remains slow in sleep apnea patients throughout the night. Sleep Med. 2003, 4, 229-234. [CrossRef]

58. Kerner, N.A.; Roose, S.P. Obstructive Sleep Apnea is Linked to Depression and Cognitive Impairment: Evidence and Potential Mechanisms. Am. J. Geriatr. Psychiatry 2016, 24, 496-508. [CrossRef]

59. Dorffner, G.; Vitr, M.; Anderer, P. The Effects of Aging on Sleep Architecture in Healthy Subjects. Adv. Exp. Med. Biol. 2015, 821, 93-100. [CrossRef]

60. Li, J.; Vitiello, M.V.; Gooneratne, N.S. Sleep in Normal Aging. Sleep Med. Clin. 2018, 13, 1-11. [CrossRef]

61. Floyd, J.A.; Medler, S.M.; Ager, J.W.; Janisse, J.J. Age-related changes in initiation and maintenance of sleep: A meta-analysis. Res. Nurs. Health 2000, 32, 106-107. [CrossRef]

62. Ohayon, M.M.; Carskadon, M.A.; Guilleminault, C.; Vitiello, M.V. Meta-analysis of quantitative sleep parameters from childhood to old age in healthy individuals: Developing normative sleep values across the human lifespan. Sleep 2004, 27, 1255-1273. [CrossRef] [PubMed]

63. Campbell, S.S.; Murphy, P.J. The nature of spontaneous sleep across adulthood. J. Sleep Res. 2007, 16, 24-32. [CrossRef] [PubMed]

64. Conte, F.; Arzilli, C.; Errico, B.M.; Giganti, F.; Iovino, D.; Ficca, G.; Giganti, F.; Iovino, D.; Ficca, G. Sleep Measures Expressing "Functional Uncertainty" in Elderlies' Sleep. Gerontology 2014, 60, 448-457. [CrossRef]

65. Landolt, H.-P.; Dijk, D.-J.; Achermann, P.; Borbély, A.A. Effect of age on the sleep EEG: Slow-wave activity and spindle frequency activity in young and middle-aged men. Brain Res. 1996, 738, 205-212. [CrossRef]

66. Klerman, E.B.; Dijk, D.-J. Age-Related Reduction in the Maximal Capacity for Sleep-Implications for Insomnia. Curr. Biol. 2008, 18, 1118-1123. [CrossRef]

67. Dijk, D.; Beersma, D.; Vandenhoofdakker, R. All night spectral analysis of EEG sleep in young adult and middle-aged male subjects. Neurobiol. Aging 1989, 10, 677-682. [CrossRef]

68. Dubé, J.; LaFortune, M.; Bedetti, C.; Bouchard, M.; Gagnon, J.F.; Doyon, J.; Evans, A.C.; Lina, J.-M.; Carrier, J. Cortical Thinning Explains Changes in Sleep Slow Waves during Adulthood. J. Neurosci. 2015, 35, 7795-7807. [CrossRef] [PubMed] 
69. Martin, N.; LaFortune, M.; Godbout, J.; Barakat, M.; Robillard, R.; Poirier, G.; Bastien, C.; Carrier, J. Topography of age-related changes in sleep spindles. Neurobiol. Aging 2013, 34, 468-476. [CrossRef] [PubMed]

70. Lo, J.C.; Sim, S.K.Y.; Chee, M.W.L. Sleep Reduces False Memory in Healthy Older Adults. Sleep 2014, 37, 665-671. [CrossRef]

71. Mander, B.A.; Rao, V.; Lu, B.; Saletin, J.M.; Lindquist, J.R.; Ancoli-Israel, S.; Jagust, W.; Walker, M.P. Prefrontal atrophy, disrupted NREM slow waves and impaired hippocampal-dependent memory in aging. Nat. Neurosci. 2013, 16, 357-364. [CrossRef]

72. Varga, A.W.; Ducca, E.L.; Kishi, A.; Fischer, E.; Parekh, A.; Koushyk, V.; Yau, P.L.; Gumb, T.; Leibert, D.P.; Wohlleber, M.E.; et al. Effects of aging on slow-wave sleep dynamics and human spatial navigational memory consolidation. Neurobiol. Aging 2016, 42, 142-149. [CrossRef] [PubMed]

73. Foley, D.J.; Monjan, A.A.; Brown, S.L.; Simonsick, E.M.; Wallace, R.B.; Blazer, D.G. Sleep complaints among elderly persons-An epidemiological study of 3 communities. SleIep 1995, 18, 425-432. [CrossRef]

74. Newman, A.B.; Enright, P.L.; Manolio, T.A.; Haponik, E.F.; Wahl, P.W.; On behalf of the Cardiovascular Health Study Research Group; Mhs, T.A.M. Sleep Disturbance, Psychosocial Correlates, and Cardiovascular Disease in 5201 Older Adults: The Cardiovascular Health Study. J. Am. Geriatr. Soc. 1997, 45, 1-7. [CrossRef] [PubMed]

75. Young, T.; E Peppard, P.; Gottlieb, D.J. Epidemiology of obstructive sleep apnea: A population health perspective. Am. J. Respir. Crit. Care Med. 2002, 165, 1217-1239. [CrossRef]

76. Altena, E.; Van Der Werf, Y.D.; Strijers, R.L.M.; Van Someren, E.J.W. Sleep loss affects vigilance: Effects of chronic insomnia and sleep therapy. J. Sleep Res. 2008, 17, 335-343. [CrossRef] [PubMed]

77. Haimov, I.; Hanuka, E.; Horowitz, Y. Chronic Insomnia and Cognitive Functioning Among Older Adults. Behav. Sleep Med. 2008, 6, 32-54. [CrossRef]

78. Ling, A.; Lim, M.L.; Gwee, X.; Ho, R.C.; Collinson, S.L.; Ng, T.-P. Insomnia and daytime neuropsychological test performance in older adults. Sleep Med. 2016, 17, 7-12. [CrossRef]

79. Prinz, P.N.; Vitaliano, P.P.; Vitiello, M.V.; Bokan, J.; Raskind, M.; Peskind, E.; Gerber, C. Sleep; EEG and mental function changes in senile dementia of the Alzheimer's type. Neurobiol. Aging 1982, 3, 361-370. [CrossRef]

80. Kabeshita, Y.; Adachi, H.; Matsushita, M.; Kanemoto, H.; Sato, S.; Suzuki, Y.; Yoshiyama, K.; Shimomura, T.; Yoshida, T.; Shimizu, H.; et al. Sleep disturbances are key symptoms of very early stage Alzheimer disease with behavioral and psychological symptoms: A Japan multi-center cross-sectional study (J-BIRD). Int. J. Geriatr. Psychiatry 2017, 32, 222-230. [CrossRef]

81. Ancoli-Israel, S.; Klauber, M.R.; Butters, N.; Parker, L.; Kripke, D.F. Dementia in institutionalized elderly: Relation to sleep apnea. J. Am. Geriatr Soc. 1991, 39, 258-263. [CrossRef]

82. Brzecka, A.; Leszek, J.; Ashraf, G.M.; Ejma, M.; Ávila-Rodriguez, M.F.; Yarla, N.S.; Tarasov, V.V.; Chubarev, V.N.; Samsonova, A.N.; Barreto, G.E.; et al. Sleep Disorders Associated With Alzheimer's Disease: A Perspective. Front. Neurosci. 2018, 12, 330-340. [CrossRef] [PubMed]

83. Gagnon, J.-F.; Petit, D.; Latreille, V.; Montplaisir, J. Neurobiology of sleep disturbances in neurodegenerative disorders. Curr. Pharm. Des. 2008, 14, 3430-3445. [CrossRef] [PubMed]

84. Rongve, A.; Boeve, B.F.; Aarsland, D. Frequency and Correlates of Caregiver-Reported Sleep Disturbances in a Sample of Persons with Early Dementia. J. Am. Geriatr. Soc. 2010, 58, 480-486. [CrossRef] [PubMed]

85. Cross, N.; Terpening, Z.; Rogers, N.L.; Duffy, S.L.; Hickie, I.B.; Lewis, S.J.; Naismith, S.L. Napping in older people 'at risk' of dementia: Relationships with depression, cognition, medical burden and sleep quality. J. Sleep Res. 2015, 24, 494-502. [CrossRef] [PubMed]

86. McCurry, S.M.; Ancoli-Israel, S. Sleep dysfunction in Alzheimer's disease and other dementias. Curr. Treat. Options Neurol. 2003, 5, 261-272. [CrossRef] [PubMed]

87. Most, E.I.; Aboudan, S.; Scheltens, P.; Van Someren, E.J. Discrepancy Between Subjective and Objective Sleep Disturbances in Early- and Moderate-Stage Alzheimer Disease. Am. J. Geriatr. Psychiatry 2012, 20, 460-467. [CrossRef]

88. Prinz, P.N.; Peskind, E.R.; Vitaliano, P.P.; Raskind, M.A.; Eisdorfer, C.; Zemcuznikov, H.N.; Gerber, C.J. Changes in the Sleep and Waking EEGs of Nondemented and Demented Elderly Subjects. J. Am. Geriatr. Soc. 1982, 30, 86-92. [CrossRef]

89. Vitiello, M.V.; Prinz, P.N.; Williams, D.E.; Frommlet, M.S.; Ries, R.K. Sleep Disturbances in Patients With Mild-Stage Alzheimer's Disease. J. Gerontol. 1990, 45, M131-M138. [CrossRef] 
90. Alzheimer, A. Über eine eigenartige Erkrankung der Hirnrinde. Allg Zeitschr f Psychiatr. $u$ Psych.-Gerichtl Med. 1907, 64, 146-148.

91. Duyckaerts, C.; Delatour, B.; Potier, M.-C. Classification and basic pathology of Alzheimer disease. Acta Neuropathol. 2009, 118, 5-36. [CrossRef]

92. Grundke-Iqbal, I.; Iqbal, K.; Tung, Y.C.; Quinlan, M.; Wisniewski, H.M.; Binder, L.I. Abnormal phosphorylation of the microtubule-associated protein tau (tau) in Alzheimer cytoskeletal pathology. Proc. Natl. Acad. Sci. USA 1986, 83, 4913-4917. [CrossRef] [PubMed]

93. Ju, Y.-E.S.; Zangrilli, M.A.; Finn, M.B.; Fagan, A.M.; Holtzman, D.M. Obstructive sleep apnea treatment, slow wave activity, and amyloid- $\beta$. Ann. Neurol. 2019, 85, 291-295. [CrossRef] [PubMed]

94. Emamian, F.; Khazaie, H.; Tahmasian, M.; Leschziner, G.D.; Morrell, M.J.; Hsiung, G.-Y.R.; Rosenzweig, I.; Sepehry, A.A. The Association Between Obstructive Sleep Apnea and Alzheimer's Disease: A Meta-Analysis Perspective. Front. Aging Neurosci. 2016, 8, 77. [CrossRef] [PubMed]

95. Caselli, R.J. Obstructive sleep apnea, apolipoprotein E e4, and mild cognitive impairment. Sleep Med. 2008, 9, 816-817. [CrossRef]

96. Osorio, R.S.; Gumb, T.; Pirraglia, E.; Varga, A.W.; Lu, S.-E.; Lim, J.; Wohlleber, M.E.; Ducca, E.L.; Koushyk, V.; Glodzik, L.; et al. Sleep-disordered breathing advances cognitive decline in the elderly. Neurology 2015, 84, 1964-1971. [CrossRef]

97. Zhu, X.; Zhao, Y. Sleep-disordered breathing and the risk of cognitive decline: A meta-analysis of 19;940 participants. Sleep Breath. 2018, 22, 165-173. [CrossRef]

98. Osorio, R.S.; Ayappa, I.; Mantua, J.; Gumb, T.; Varga, A.; Mooney, A.M.; Burschtin, O.E.; Taxin, Z.; During, E.; Spector, N.; et al. The interaction between sleep-disordered breathing and apolipoprotein E genotype on cerebrospinal fluid biomarkers for Alzheimer's disease in cognitively normal elderly individuals. Neurobiol. Aging 2014, 35, 1318-1324. [CrossRef]

99. Ju, Y.-E.S.; Finn, M.B.; Sutphen, C.L.; Herries, E.M.; Jerome, G.M.; Ladenson, J.H.; Crimmins, D.L.; Fagan, A.M.; Holtzman, D.M. Obstructive sleep apnea decreases central nervous system-derived proteins in the cerebrospinal fluid. Ann. Neurol. 2016, 80, 154-159. [CrossRef]

100. Van Erum, J.; Van Dam, D.; Sheorajpanday, R.; De Deyn, P.P. Sleep architecture changes in the APP23 mouse model manifest at onset of cognitive deficits. Behav. Brain Res. 2019, 373, 112089. [CrossRef]

101. Nitsch, R.M.; Farber, S.A.; Growdon, J.H.; Wurtman, R.J. Release of amyloid beta-protein precursor derivatives by electrical depolarization of rat hippocampal slices. Proc. Natl. Acad. Sci. USA 1993, 90, 5191-5193. [CrossRef]

102. Bero, A.W.; Yan, P.; Roh, J.H.; Cirrito, J.R.; Stewart, F.R.; Raichle, M.E.; Lee, J.-M.; Holtzman, D.M. Neuronal activity regulates the regional vulnerability to amyloid- $\beta$ deposition. Nat. Neurosci. 2011, 14, 750-756. [CrossRef]

103. Bateman, R.J.; Wen, G.; Morris, J.C.; Holtzman, D.M. Fluctuations of CSF amyloid- $\beta$ levels: Implications for a diagnostic and therapeutic biomarker. Neurology 2007, 68, 666-669. [CrossRef]

104. Lucey, B.P.; Hicks, T.J.; McLeland, J.S.; Toedebusch, C.D.; Boyd, J.; Elbert, N.L.; Patterson, B.W.; Baty, J.; Morris, J.C.; Ovod, V.; et al. Effect of sleep on overnight cerebrospinal fluid amyloid $\beta$ kinetics. Ann. Neurol. 2018, 83, 197-204. [CrossRef]

105. Kang, J.-E.; Lim, M.M.; Bateman, R.J.; Lee, J.J.; Smyth, L.P.; Cirrito, J.R.; Fujiki, N.; Nishino, S.; Holtzman, D.M. Amyloid- Dynamics Are Regulated by Orexin and the Sleep-Wake Cycle. Science 2009, 326, 1005-1007. [CrossRef]

106. Musiek, E.S.; Holtzman, D.M. Mechanisms linking circadian clocks, sleep, and neurodegeneration. Science 2016, 354, 1004-1008. [CrossRef]

107. Ooms, S.; Overeem, S.; Besse, K.; Rikkert, M.O.; Verbeek, M.; Claassen, J.A.H.R. Effect of 1 Night of Total Sleep Deprivation on Cerebrospinal Fluid $\beta$-Amyloid 42 in Healthy Middle-Aged Men. JAMA Neurol. 2014, 71, 971-977. [CrossRef]

108. Shokri-Kojori, E.; Wang, G.-J.; Wiers, C.E.; Demiral Şükrü, B.; Guo, M.; Kim, S.W.; Lindgren, E.; Ramirez, V.; Zehra, A.; Freeman, C.; et al. $\beta$-Amyloid accumulation in the human brain after one night of sleep deprivation. Proc. Natl. Acad. Sci. USA 2018, 115, 4483-4488. [CrossRef]

109. Ju, Y.-E.S.; McLeland, J.S.; Toedebusch, C.D.; Xiong, C.; Fagan, A.M.; Duntley, S.P.; Morris, J.C.; Holtzman, D.M. Sleep quality and preclinical Alzheimer disease. JAMA Neurol. 2013, 70, 587-593. [CrossRef] 
110. Varga, A.W.; Wohlleber, M.E.; Giménez, S.; Romero, S.; Alonso, J.F.; Ducca, E.L.; Kam, K.; Lewis, C.; Tanzi, E.B.; Tweardy, S.; et al. Reduced Slow-Wave Sleep Is Associated with High Cerebrospinal Fluid A $\beta 42$ Levels in Cognitively Normal Elderly. Sleep 2016, 39, 2041-2048. [CrossRef]

111. Mander, B.A.; Marks, S.M.; Vogel, J.W.; Rao, V.; Lu, B.; Saletin, J.M.; Ancoli-Israel, S.; Jagust, W.J.; Walker, M.P. $\beta$-amyloid disrupts human NREM slow waves and related hippocampus-dependent memory consolidation. Nat. Neurosci. 2015, 18, 1051-1057. [CrossRef]

112. Murphy, M.; Riedner, B.A.; Huber, R.; Massimini, M.; Ferrarelli, F.; Tononi, G. Source modeling sleep slow waves. In Proceedings of the Proceedings of the National Academy of Sciences. Proc. Natl. Acad. Sci. USA 2009, 106, 1608-1613. [CrossRef]

113. Buckner, R.L.; Snyder, A.Z.; Shannon, B.J.; LaRossa, G.; Sachs, R.; Fotenos, A.F.; Sheline, Y.I.; Klunk, W.E.; Mathis, C.A.; Morris, J.C.; et al. Molecular; structural; and functional characterization of Alzheimer's disease: Evidence for a relationship between default activity; amyloid; and memory. J. Neurosci. 2005, 25, 7709-7717. [CrossRef]

114. Jack, C.R.; Knopman, D.S.; Jagust, W.J.; Shaw, L.M.; Aisen, P.S.; Weiner, M.W.; Petersen, R.C.; Trojanowski, J.Q. Hypothetical model of dynamic biomarkers of the Alzheimer's pathological cascade. Lancet Neurol. 2010, 9 , 119-128. [CrossRef]

115. Elman, J.A.; Oh, H.; Madison, C.M.; Baker, S.L.; Vogel, J.W.; Marks, S.M.; Crowley, S.; O’Neil, J.P.; Jagust, W.J. Neural compensation in older people with brain amyloid-beta deposition. Nat. Neurosci. 2014, 17, 1316-1318. [CrossRef]

116. Mattsson, N.; Insel, P.S.; Aisen, P.S.; Jagust, W.; Mackin, S.; Weiner, M.; Alzheimer's Disease Neuroimaging Initiative. Brain structure and function as mediators of the effects of amyloid on memory. Neurology 2015, 84, 1136-1144. [CrossRef]

117. Leow, A.D.; Yanovsky, I.; Parikshak, N.; Hua, X.; Lee, S.; Toga, A.W.; Jack, C.R.; Bernstein, M.A.; Britson, P.J.; Gunter, J.L.; et al. Alzheimer's Disease Neuroimaging Initiative: A one-year follow up study using tensor-based morphometry correlating degenerative rates, biomarkers and cognition. NeuroImage 2009, 45, 645-655. [CrossRef]

118. Wang, C.; Holtzman, D.M. Bidirectional relationship between sleep and Alzheimer's disease: Role of amyloid, tau, and other factors. Neuropsychopharmacology 2019, 45, 104-120. [CrossRef]

119. Lucey, B.P.; McCullough, A.; Landsness, E.C.; Toedebusch, C.D.; McLeland, J.S.; Zaza, A.M.; Fagan, A.M.; McCue, L.; Xiong, C.; Morris, J.C.; et al. Reduced non-rapid eye movement sleep is associated with tau pathology in early Alzheimer's disease. Sci. Transl. Med. 2019, 11, eaau6550. [CrossRef]

120. Kam, K.; Parekh, A.; Sharma, R.A.; Andrade, A.; Lewin, M.; Castillo, B.; Bubu, O.M.; Chua, N.J.; Miller, M.D.; Mullins, A.E.; et al. Sleep oscillation-specific associations with Alzheimer's disease CSF biomarkers: Novel roles for sleep spindles and tau. Mol. Neurodegener. 2019, 14, 10-22. [CrossRef]

121. Holth, J.K.; Fritschi, S.K.; Wang, C.; Pedersen, N.P.; Cirrito, J.R.; Mahan, T.E.; Finn, M.B.; Manis, M.; Geerling, J.C.; Fuller, P.M.; et al. The sleep-wake cycle regulates brain interstitial fluid tau in mice and CSF tau in humans. Science 2019, 363, 880-884. [CrossRef]

122. Braak, H.; Del Tredici, K. The pathological process underlying Alzheimer's disease in individuals under thirty. Acta Neuropathol. 2011, 121, 171-181. [CrossRef]

123. Zhu, Y.; Zhan, G.; Fenik, P.; Brandes, M.; Bell, P.; Francois, N.; Shulman, K.; Veasey, S. Chronic Sleep Disruption Advances the Temporal Progression of Tauopathy in P301S Mutant Mice. J. Neurosci. 2018, 38, 10255-10270. [CrossRef]

124. Di Meco, A.; Joshi, Y.B.; Praticò, D. Sleep deprivation impairs memory; tau metabolism; and synaptic integrity of a mouse model of Alzheimer's disease with plaques and tangles. Neurobiol. Aging 2014, 35, 1813-1820. [CrossRef]

125. Rothman, S.M.; Herdener, N.; Frankola, K.A.; Mughal, M.R.; Mattson, M.P. Chronic mild sleep restriction accentuates contextual memory impairments; and accumulations of cortical Ab and pTau in a mouse model of Alzheimer's disease. Brain Res. 2013, 1529, 200-208. [CrossRef]

126. Winer, J.R.; Mander, B.A.; Helfrich, R.F.; Maass, A.; Harrison, T.M.; Baker, S.L.; Knight, R.T.; Jagust, W.J.; Walker, M.P. Sleep as a Potential Biomarker of Tau and $\beta$-Amyloid Burden in the Human Brain. J. Neurosci. 2019, 39, 6315-6324. [CrossRef]

127. Mendelsohn, A.R.; Larrick, J.W. Sleep Facilitates Clearance of Metabolites from the Brain: Glymphatic Function in Aging and Neurodegenerative Diseases. Rejuvenation Res. 2013, 16, 518-523. [CrossRef] 
128. Iliff, J.J.; Wang, M.; Liao, Y.; Plogg, B.A.; Peng, W.; Gundersen, G.A.; Benveniste, H.; Vates, G.E.; Deane, R.; Goldman, S.A.; et al. A Paravascular Pathway Facilitates CSF Flow Through the Brain Parenchyma and the Clearance of Interstitial Solutes, Including Amyloid. Sci. Transl. Med. 2012, 4, 147ra111. [CrossRef]

129. Boespflug, E.L.; Iliff, J.J. The Emerging Relationship Between Interstitial Fluid-Cerebrospinal Fluid Exchange, Amyloid- $\beta$, and Sleep. Boil. Psychiatry 2018, 83, 328-336. [CrossRef]

130. Xie, L.; Kang, H.; Xu, Q.; Chen, M.J.; Liao, Y.; Thiyagarajan, M.; O’Donnell, J.; Christensen, D.J.; Nicholson, C.; Iliff, J.J.; et al. Sleep Drives Metabolite Clearance from the Adult Brain. Science 2013, 342, 373-377. [CrossRef]

131. Kress, B.T.; Iliff, J.J.; Xia, M.; Wang, M.; Wei, H.S.; Zeppenfeld, U.; Xie, L.; Kang, H.; Xu, Q.; Liew, J.A.; et al. Impairment of paravascular clearance pathways in the aging brain. Ann. Neurol. 2014, 76, 845-861. [CrossRef]

132. Tarasoff-Conway, J.M.; Carare, R.O.; Osorio, R.S.; Glodzik, L.; Butler, T.; Fieremans, E.; Axel, L.; Rusinek, H.; Nicholson, C.; Zlokovic, B.V.; et al. Clearance systems in the brain-Implications for Alzheimer disease. Nat. Rev. Neurol. 2015, 11,457-470. [CrossRef]

133. Gallina, P.; Scollato, A.; Conti, R.; Di Lorenzo, N.; Porfirio, B. A $\beta$ Clearance, "hub" of Multiple Deficiencies Leading to Alzheimer Disease. Front. Aging Neurosci. 2015, 7, 142. [CrossRef]

134. Rasmussen, M.K.; Mestre, H.; Nedergaard, M. The glymphatic pathway in neurological disorders. Lancet Neurol. 2018, 17, 1016-1024. [CrossRef]

135. Smith, A.J.; Verkman, A.S. The "glymphatic" mechanism for solute clearance in Alzheimer's disease: Game changer or unproven speculation? FASEB J. 2018, 32, 543-551. [CrossRef]

136. Ju, Y.-E.S.; Ooms, S.J.; Sutphen, C.; Macauley, S.L.; Zangrilli, M.A.; Jerome, G.; Fagan, A.M.; Mignot, E.; Zempel, J.M.; Claassen, J.A.; et al. Slow wave sleep disruption increases cerebrospinal fluid amyloid- $\beta$ levels. Brain 2017, 140, 2104-2111. [CrossRef]

137. Diekelmann, S.; Born, J. The memory function of sleep. Nat. Rev. Neurosci. 2010, 11, 114-126. [CrossRef]

138. Zhang, X.; Zhong, W.; Brankačk, J.; Weyer, S.W.; Müller, U.C.; Tort, A.B.L.; Draguhn, A. Impaired theta-gamma coupling in APP-deficient mice. Sci. Rep. 2016, 6, 21948. [CrossRef]

139. Nakazono, T.; Lam, T.N.; Patel, A.Y.; Kitazawa, M.; Saito, T.; Saido, T.C.; Igarashi, K.M. Impaired In Vivo Gamma Oscillations in the Medial Entorhinal Cortex of Knock-in Alzheimer Model. Front. Syst. Neurosci. 2017, 11, 48-60. [CrossRef]

140. Montgomery, S.M.; Sirota, A.; Buzsáki, G. Theta and gamma coordination of hippocampal networks during waking and rapid eye movement sleep. J. Neurosci. 2008, 28, 6731-6741. [CrossRef]

141. Westerberg, C.E.; Mander, B.A.; Florczak, S.M.; Weintraub, S.; Mesulam, M.-M.; Zee, P.C.; Paller, K.A. Concurrent Impairments in Sleep and Memory in Amnestic Mild Cognitive Impairment. J. Int. Neuropsychol. Soc. 2012, 18, 490-500. [CrossRef]

142. Liguori, C.; Romigi, A.; Nuccetelli, M.; Zannino, S.; Sancesario, G.; Martorana, A.; Albanese, M.; Mercuri, N.B.; Izzi, F.; Bernardini, S.; et al. Orexinergic System Dysregulation, Sleep Impairment, and Cognitive Decline in Alzheimer Disease. JAMA Neurol. 2014, 71, 1498-1505. [CrossRef]

143. Song, Y.; Blackwell, T.; Yaffe, K.; Ancoli-Israel, S.; Redline, S.; Stone, K.L. Osteoporotic Fractures in Men (MrOS) Study Group. Relationships Between Sleep Stages and Changes in Cognitive Function in Older Men: The MrOS Sleep Study. Sleep 2015, 38, 411-421. [PubMed]

144. Humpel, C. Identifying and validating biomarkers for Alzheimer's disease. Trends Biotechnol. 2011, $29,26-32$. [CrossRef] [PubMed]

(C) 2020 by the authors. Licensee MDPI, Basel, Switzerland. This article is an open access article distributed under the terms and conditions of the Creative Commons Attribution (CC BY) license (http://creativecommons.org/licenses/by/4.0/). 